\begin{tabular}{|c|c|c|c|}
\hline \multirow{2}{*}{ 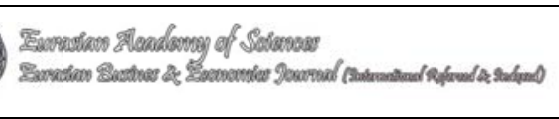 } & \multicolumn{3}{|c|}{$\begin{array}{c}\text { Eurasian Academy of Sciences } \\
\text { Eurasian Business \& Econormics Journal }\end{array}$} \\
\hline & 2015 & Volume:1 & S: $86-93$ \\
\hline \multicolumn{4}{|c|}{$\begin{array}{l}\text { Published Online April } 2015 \text { (http://busecon.eurasianacademy.org) } \\
\text { http://dx.doi.org/10.17740/eas.econ.2015-V1-04 }\end{array}$} \\
\hline
\end{tabular}

\title{
THE EFFECT OF THE COMPONENTS OF LOGISTICS PERFORMANCE INDEX ON GROSS DOMESTIC PRODUCT: CONCEPTUAL MODEL PROPOSAL
}

\author{
Nagehan Uca*, Mustafa Emre Civelek**, Murat Çemberci***
}

İstanbul Ticaret Üniversitesi*, İstanbul Ticaret Üniversitesi**, İstanbul Ticaret Üniversitesi ${ }^{* * *}$

E-mail: nuca@ticaret.edu.tr*,ecivelek@ticaret.edu.tr**,mcemberci@ticaret.edu.tr***

Copyright (C) 2015 Nagehan Uca / Mustafa Emre Civelek / Murat Çemberci. This is an open access article distributed under the Eurasian Academy of Sciences License, which permits unrestricted use, distribution, and reproduction in any medium, provided the original work is properly cited.

\begin{abstract}
Domestic and foreign trade are the most important components of the logistics sector. Logistics is related with planning, application and control of flowing of product, service and information between production and consumption areas. The most important indicators to represent the level of development of a country are economic indicators. Developments in the logistics sector contribute production and consumption activities around the World. In this context, logistics sector has an important role in social and economic development. The aim of this study is to designate the relation between gross domestic product (GDP) and logistics performance index (LPI) and differentiate the effects of the components of the LPI on GDP. As a result of the analysis conducted, the effects of Customs and Infrastructure dimensions of LPI on GDP are statistically meaningful.
\end{abstract}

Keywords: Logistics, LPI, GDP

JEL-Clasification: F19

\section{Lojistik Performans Endeksi Bileşenlerinin Gayri Safi Milli Hasıla Üzerine Etkisi: Kavramsal Model Önerisi}

ÖZET: Ulusal ve uluslararası ticaret, lojistik sektörünün en önemli bileşenlerindendir. Lojistik, üretim ve tüketim noktaları arasındaki ürün, hizmet ve bilgi akışının, planlanması, uygulaması ve kontrol edilmesi süreci ile ilgilenmektedir. Ülkenin gelişmişlik ve kalkınmışlık düzeyini anlamamızdaki en önemli göstergeler ekonomik göstergelerdir. Dünya genelinde sektördeki gelişmeler üretim ve tüketim faaliyetlerine önemli katkı sağlamaktadır. $\mathrm{Bu}$ bağlamda, lojistik sektörünün sosyal ve ekonomik kalkınmada kritik bir rolü bulunmaktadır. Bu çalışmanın amacı, Gayri Safi Milli Hasıla ile Lojistik Performans Endeksi arasındaki ilişkinin belirlenmesi ve lojistik performans göstergelerinin ülkelerin gayri safi milli hasılası üzerindeki etkisinin incelenmesidir. Literatürde bu konuda yapılmış fazla çalışma bulunmamaktadır. Yapılan analizler neticesinde Lojistik Performans Endeksinin alt boyutları 
olan "gümrüklerin ve gümrükleme süreçlerinin verimliliğii" ve "ticaret ve taşımacılıkla ilgili altyapı kalitesi" ile gayri safi milli hasıla arasında bir ilişkinin varlığı istatistiksel olarak anlamlı bulunmuştur.

Anahtar Kelimeler: Lojistik, LPE, GSMH

\section{Giriş}

Türkiye'de lojistik sektörüne ait, pazar büyüklüğü, firma sayısı, istihdam, ciro, üretilen katma değer, maliyetler gibi konularda veri bulmak oldukça zordur. Uluslararası kuruluşların hazırladığı raporlara ve akademik yayınlara bakıldığında genellikle ulaştırma ve haberleşme sektörüne ait verilerin lojistik sektörü verileri yerine ikame edildiği gözlenmektedir. Bunun dışında, dış ticaret hacimlerinden, yük trafiğinden ve gümrük kayıtlarından da yararlanılabilmektedir. $\mathrm{AB}$ ve $\mathrm{ABD}$ verilerine dayalı değerlendirme sonuçlarına göre, lojistiğin GSMH'deki payı \% 10 civarında gerçekleşmektedir. Türkiye'nin 2011 yılı GSMH'si yaklaş1k 750 milyar dolar ise, lojistik sektörünün Türkiye'deki pazar büyüklüğü 70 milyar doların üzerinde olmalıdır. Gerçekte, lojistik firmalarının ciroları henüz bu değerin çok altında olduğundan hem istihdam hem de yatırım açısından sektörün büyük bir potansiyeli bulunmaktadır (Bayraktutan, Tüylüoğlu, \& Özbilgin, 2012). Sektörün piyasa büyüklüğü hakkında farklı değerlendirmelere rastlanmaktadır. Agility'nin Emerging Markets Logistics Index 2014 raporunda sektörün profesyonellerinin \%72'si dünya ekonomisin ve ticaret hacmindeki büyümenin sektörü etkileyeceğini belirtmiştir. (Agility, 2014) 2013 yılında Deloitte Türkiye'nin Lojistik sektörü ile ilgili yaptığı araştırmada Lojistik sektörü (Ulaştırma ve haberleşme sektörü) büyüme oranlarının gayri safi milli hasıla verileri ile paralel ilerlediği ortaya konulmuştur (Deloitte, 2013). Dünyada lojistik sektörünün potansiyeli 6 trilyon dolar olarak tahmin edilmektedir. Sektörün gayrisafi milli hasıladan aldığı pay, gelişmiş ülkelerde yüzde 8 ile 10 arasındadır. Sektör büyümesi ise ortalama \% 10 ile, \% 3-4 aralığında büyüyen dünya ekonomisinin oldukça üzerinde bir performans sergilemektedir. Lojistik iş potansiyeli son beş yıldır, her yıl dünya GSMH artışına göre \% 5 oranında artarken lojistik pazarı küreselleşme, dış kaynak kullanımının artması, ölçeklerin büyümesiyle \% 20 oranında artmaktadır. Türkiye'de ise Gayri Safi Milli Hasıla'nın \% 10-13'üne denk gelen 30 milyar dolarlık bir potansiyel pazardan söz edilmektedir (Müsiad, 2013).

Ekonomik büyüme bir ülkede, üretim kapasitesinin, üretimin ve dolayısıyla milli geliri artmasını ifade eder. Ülkeler için önemli göstergelerden biri olan Gayri Safi Milli Hasıla (GSMH) rakamları ekonominin genel durumu hakkında da bilgi veren sayısal ölçülerdendir. Bu çalışmada GSMH bağımlı değişken olarak kullanılmıştır.

Makalede konu edilen diğer bir ölçüt ise Lojistik Performans Endeksidir. Dünya Bankası organizasyonunda çeşitli kurum ve kuruluşların destekleriyle yürütülen kapsamlı bir ankete dayanan araştırmadır. Dünya Bankası tarafından ilk olarak 2007 yayınlanan endeks sırasıyla 2010, 2012 ve son olarak 2014 yılında yayınlanmıştır. Altı farklı lojistik kriter kullanarak ülkeler bazında Lojistik Performans Endeksi ölçüm sistemi geliştirilmiş ve bu şekilde ülkelerin lojistik açıdan gelişmişlik düzeyinin ölçülmesi gerçekleştirilmiştir. Bu performans endeksinin hesabında, iş hacminin etkisinden ziyade, lojistik alt yapı ve sistemlerin etkinliği çok daha fazla önemlidir. Puanlamaların hesabında birebir görüşmeler ve denetimler dikkate alınmaktadır. (Tanyas \& Arıkan, 2013) Tüm dünyanın iş ve lojistik çevrelerin yakından takip 
ettiği bu endeks, Dünya Bankası, lojistik hizmet sağlayıcıları ve akademisyenlerin ortak bir çalışmasının ürünü olup, Endeksi belirleyen "anket çalışması" 160 ülkenin kıyaslanmasına imkân verirken ülkelerin sıkıntılı alanları ve firsatları belirlemesine ve lojistik performanslarını arttırmasına olanak sağlamaktadır (UND, 2014).

\section{Kavramsal Çerçeve}

2009 yılı lojistik performans endeksi 130 ülkede uluslararası lojistik şirketlerinde çalışan yaklaşık 1000 profesyonel yöneticiye uygulanan anketler sonucunda elde edilen verilerle belirlenmiştir. Anket yapılan yöneticilerin $\% 45$ 'i orta gelir düzeyindeki, \%10'u düşük gelir düzeyindeki, $\% 45$ 'i ise yüksek gelir düzeyindeki ülkelerdeki firmalarda çalışan yöneticilerdir. $\mathrm{Bu}$ yöneticilerin $\% 45^{\prime}$ i büyük firmalarda , $\% 55$ 'i ise küçük ve orta büyüklükteki firmalarda çalışmaktadır. Ayrıca bu yöneticilerin \%35'i yüksek düzeyli idareci, \%25'i sahada yönetici konumunda, \%24'ü bölüm yöneticisi ve \%26's1 günlük faaliyetlerle ilgilenen düşük düzeyli yöneticidir (Burmaoğlu, 2012).

Anket uygulanan yöneticilerden ülkelerindeki lojistik sektörünü aşağıda açıklanan altı boyuta göre 5'li likert ölçeği ile değerlendirmeleri istenmiştir.

- Gümrüklerin ve Gümrükleme Süreçlerinin Verimliliği (hız, süreçlerin öngörülebilirliği ve basitliği, sınır kapılarından geçiş kolaylığı, vb.)

- Ticaret ve Taşımacılıkla İlgili Altyapı Kalitesi (limanlar, demiryolları, karayolları, bilişim teknolojileri, vb.)

- Yüklemede Rekabetçi Fiyatlama

- Lojistik Hizmetlerinin Kalite ve Yeterliliği (lojistik şirketler, gümrük müşavirleri, vb.)

- Sevkiyatların İzlenebilirliği

- Yüklemelerin Zamanında Varış Yerine Ulaşması şeklinde sıralanabilir.

Türkiye'nin LPE gelişimine bakıldı ğında; 2007 yılında 3,15 puanla 34. sırada, 2010 yılında 3,22 puanla 39. sirada, 2012 y1lında 3,51 puanla 27. sirada, 2014 yılında 3,50 puanla 30. sırada yer almıştır.

Ülkelere göre endeksler yıllar itibarıyla incelendiğinde İsveç, Norveç, Lüksemburg ne kadar yükleme ve boşaltma açısından yoğun trafik içermeyen ülkeler olsa da LPE endeksine göre, Dünya üzerindeki lojistik mükemmelliğe sahip ülkeler olarak de ğerlendirilmektedir. Singapur, Almanya ve Hollanda sürekli olarak ilk sıralarda yer almaktadır. Türkiye ise 2014 yılına kadar inişli ve çıkışlı bir puan seyri izlemiş, 2014 yılında puanı 3,50'ye düşmüş ve 30 . sıraya gerilemiştir. Bunun dışında tüm komşu ülkelere göre LPE puanı en fazla olan ülke Türkiye'dir.

Listenin orta sıralarında bulunan ülkelerin daha üst sıralarda yer alması önündeki en büyük engel olarak yetersiz altyapı ve bilgi teknolojisi yatırımları gösterilebilir. Listenin 40 ve üstü sıralarındaki ülkelerde ise operasyonların analizi ve etkinlik artırılması, öncelikli hedef olarak belirlenmektedir.

2007 yılında yapılan değerlendirmede 7 kriter söz konusu iken daha sonraki değerlendirmeler 6 kriter üzerinden yapılmış ve yurtiçi lojistik maliyetler kriteri 2010 y1lı itibarıyla değerlendirme dışı bırakılmıştır.

Türkiye açısından en çok ilerlemenin "Lojistik hizmetlerin kalitesi ve rekabetçiliği” kriterinde olduğu, en düşük puanlı kriterin "Rekabetçi maliyetlerle taşıma organizasyonu kolaylığı" ve en yüksek puanlı kriterin ise "Sevkiyatların izlenebilirliği” olduğu görülmektedir. Dünya 
ekonomik büyüklük sıralamasında 17. olan ülkemizin lojistik performans indeksinde de istenen düzeye gelebilmesi için ülke lojistik planlamasında Dünya Bankası LPE çalışmasının dikkate alınması gerekmektedir (Loder, 2014).

Lojistik Performans Endeksin ölçülmesinde kullanılan altı boyut açısından Türkiye'nin Durumu aşağıdaki gibi özetlenebilir:

- Gümrüklerin ve Gümrükleme Süreçlerinin Verimliliği: 2014 yılı Lojistik Performans Endeksinin uluslararası kısmında yer alan altı bileşenden ilki olan "Gümrük İşlemlerinin Verimliliği” alanında Türkiye 2012 yılına göre iki sıra gerileyerek 160 ülke arasında 34 üncü sırada yer almıştır. Türkiye bu alanda 3,23 puan almış ve verimlilik düzeyi ortanın üstü olarak değerlendirilmiştir.

- Ticaret ve Taşımacılıkla İlgili Altyapı Kalitesi: 2014 LPE endeksine göre Türkiye “Ticaret ve Taşımacılık ile İlgili Altyapının Kalitesi”" alanında 2012 yılı değerlerine göre iki sıra gerileyerek 27 inci sırada yer almıştır. Türkiye bu alanda 3,53 puan almış ve altyapı kalitesi iyiye yakın olarak değerlendirilmiştir.

- Yüklemede Rekabetçi Fiyatlama: 2014 LPE Endeksine göre, Türkiye "Rekabetçi Fiyatla Sevkiyat Gönderebilme Kolaylığı” alanında 2012 yılına göre 18 sıra gerileyerek 160 ülke arasında 48 inci sırada yer almıştır. Türkiye bu alanda 3,18 puan almış ve uygun fiyatla sevkiyat gönderebilme kolaylığı ortanın üstü olarak değerlendirilmiştir.

- Lojistik Hizmetlerinin Kalite ve Yeterliliği: 2014 LPE Endeksine göre, Türkiye "Lojistik Hizmetlerin Yeterliliği ve Kalitesi" alanında 2012 yılına göre dört sıra yükselerek 160 ülke arasında 22 inci sırada yer almıştır. Türkiye bu alanda 3,64 puan almış ve lojistik hizmetlerin yeterliliği ve kalitesi "iyiye yakın" olarak değerlendirilmiştir.

- Sevkiyatların İzlenebilirliği: 2014 LPE endeksine göre, Türkiye "Sevkiyatların İzleme ve Takip Edilebilirliği” alanında 2012 yılına göre 10 basamak yükselerek 160 ülke arasında 19 uncu sırada yer almıştır. Türkiye bu alanda 3,77 puan almış ve sevkiyatların izleme ve takip edilebilirliği iyiye yakın olarak değerlendirilmiştir.

- Yüklemelerin Zamanında Varış Yerine Ulaşması: 2014 LPE endeksine göre, Türkiye “Alıcıya Zamanında Ulaşan Sevkiyatların Sıklığı” alanında 2012 yılına göre 14 sıra düşerek 160 ülke arasında 41 inci sırada yer almıştır. Türkiye bu alanda 3,68 puan aldığından sevkiyatların alıcılara sıklıkla zamanında ulaştığı değerlendirilmiştir.” (RYKGM, 2014).

LPE bu alt1 performans boyutunun toplamından oluşan bir göstergesidir. LPE oluşturularken kullanılan ankette eksik cevaplanan sorular enterpolasyon yöntemiyle tamamlanmıştır. Eksik cevaplar bu sorulara diğerleri tarafindan verilen cevapların ülke ortalaması alınarak ve eksik cevap veren kişinin diğer sorulara verdiği cevapların ülke ortalamasına göre sapma değerleri de dikkate alınarak tamamlanmış ve bu şekilde değerlendirmeye tabi tutulmuştur. LPE temel bileşen analizi yöntemi kullanılarak bahsedilen altı boyuttan oluşturulmuştur. Temel bileşenler analizinde ülke içinde anket yapılan yöneticilerin verdikleri cevapların ortalamaları kullanılmıştır. Sonuçlar temel bileşen analizine tabi tutulmadan önce örneklem ortalamaları çıkarılarak ve standart sapmaya bölünerek veri standardize edilmiştir. Sonuçta LPE temel bileşenler analizi sonrası elde edilen değerlerin ağırlıklı ortalamasıdır (Burmaoğlu, 2012). 
LPE verilerinin önemli tarafı, ülkeler verileri için belirlenmiş olan $\% 80$ güven aralığıdır. Güven aralığından ülkelerin LPE sonuçlarının alt ve üst sınırlarını tesbit etmek için faydalanılmıştır. Bu sınırlar LPE sonuçlarının anket toplanarak elde edilldiğini ve örneklem hatasının olabileceğini göstermek için belirlenmiştir. Güven aralığı hesaplanırken LPE değerlerinin standart hatası ülke bazında anketi dolduran tüm denekler için hesaplanmıştır. Ülkelerin aldığı değerler bu sinırlardan alt ya da üst sınıra yakıı olmalarına göre sıralanmışlardır (Arvis, Saslavsky, Ojala, Shepherd, Busch, \& Raj, 2014).

\section{Araștırma Yöntemi ve Modeli}

Yapısal Eşitlik Modeli son yıllardaki bilimsel araştırmalarda yaygın olarak kullanılan bir istatistiksel tekniktir. $\mathrm{Bu}$ yöntemin yaygınlaşmasının nedenlerinden biri, ölçülen değişkenlerdeki ölçüm hatalarını hesaba katmasıdır. Bir başka neden ise modelde bulunan ilişkilere yönelik gerekiyorsa yeni düzenlemeler tavsiye etmesidir. Bu şekilde ölçüm hatalarını azaltmaktadır. Yapısal Eşitlik Modeli Regresyon Modelinden farklı olarak kovaryans matrisini esas alır. Regresyon modellerinde ise korelasyon matrisi esas alınmaktadır. Regresyon analizinde her bir ilişki için ayrı ayrı regresyon analizleri yapılması gerekirken YEM ile yapılan analizlerde değişkenler arasında belirlenen tüm ilişkiler bir analizle anlaş1labilmektedir (Dursun \& Kocagöz, 2010).

$\mathrm{Bu}$ araştırmada geliştirilen hipotezleri test etmek için temel istatistiksel analiz aracı olarak Yapısal Eşitlik Modeli (YEM) kullanılmıştır. Lojistik Performans Endeksini oluşturan boyutların her birinin Gayri Safi Milli Hasıla (GSMH) ile ilişkisi araştırmanın hipotezlerini oluşturmaktadır.

\section{Şekil 1. Araştırma Modeli}

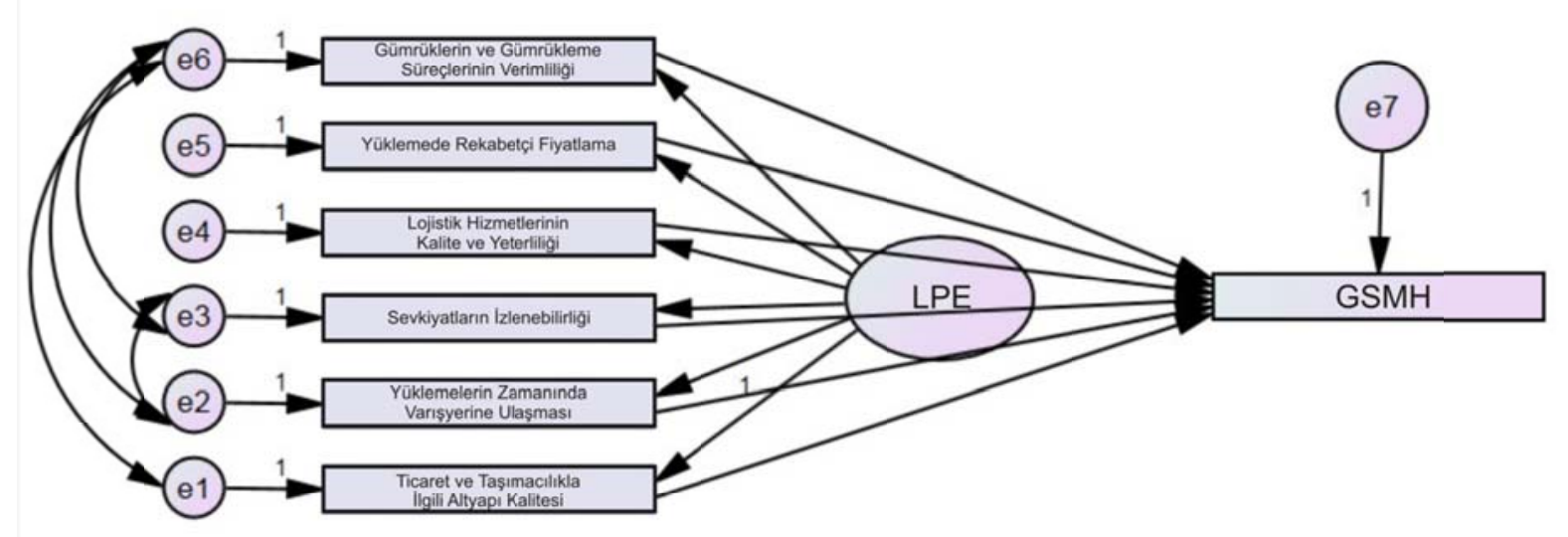

Şekil 1.'de Lojistik Performans Endeksinin alt boyutlarının GSMH üzerine etkilerini öneren kavramsal model gösterilmiştir. Modeldeki hata terimleri arasında model tarafından tavsiye edilen düzenlemelere göre kovaryans ilişkileri gösterilmiştir. 
Tablo 1. Hipotezlerin Özeti

$\mathrm{H}_{1}$ : “Gümrüklerin ve Gümrükleme Süreçlerinin Verimliliği” ile "GSMH” arasında ilişki vardir.

$\mathrm{H}_{2}$ : "Yüklemede Rekabetçi Fiyatlama" ile "GSMH" arasında ilişki vardır.

H3: "Lojistik Hizmetlerinin Kalite ve Yeterliliği” ile "GSMH” arasında ilişki vardır.

H4: "Sevkiyatların İzlenebilirliği” ile “GSMH” arasında ilişki vardır.

$\mathrm{H}_{5}$ : "Yüklemelerin Zamanında Varış Yerine Ulaşması" ile "GSMH” arasında ilişki vardır.

$\mathrm{H}_{6}$ : "Ticaret ve Taşımacılıkla İlgili Altyapı Kalitesi” ile "GSMH” arasında ilişki vardır.

Tablo 1'de hipotezler birlikte verilmektedir. Hipotezler Lojistik Performans Endeksinin her bir alt boyutu için ayrı ayrı oluşturulmuştur.

\section{Veri Analizi ve Sonuçlar}

Model ile eldeki verilerin uyumluluğu çeşitli uyum ölçeklerine (fit indices) göre değerlendirilmektedir. CMIN/DF, CFI, TLI, GFI, RMSA ölçekleri literatürde kabul görmüş ölçeklerdir (Çemberci, 2012).

CMIN (The Likelihood Ratio Chi-Square Test) ki-kare olabilirlik oranı testidir. Bu test öngörülen model ile elde edilen model arasındaki uygunluğu göstermektedir. CMIN/DF oranının 3'ten küçük olması modelin genel uyumunun kabul edilebilir sınırlar içerisinde olduğunu göstermektedir (Meydan \& Şeşen, 2011). CFI Uyum İndeksi değişkenler arasında herhangi bir ilişkinin bulunmadığ karşılaştıran artımsal bir uyum istatistiğidir. 0 ile 1 arasında değer alır ve 0,90 üzeri değer iyi uyumu gösterir (Çemberci, 2012). AGFI Uyum İndeksi serbestlik derecesi dikkate alınarak hesaplanır. Örneklem hacmi yükseldiğinde AGFI değeri yükselmektedir. AGFI değeri 0 ile 1 arasında değişir. 0,90 üzeri değerler uyumun iyi olduğunu göstermektedir (Bayram, 2013). GFI Uyum İndeksi model tarafından açıklanan varyans ve kovaryansın derecesini gösteren bir indekstir. AGFI Uyum İndeksinde olduğu gibi GFI Uyum İndeksinde örneklem hacmi yükseldikçe GFI değeri de yükselir. Bu durum doğru sonuç alınmasını önleyebilir. GFI değeri 0 ile 1 arasında değişir. 0,90 ve 0,95 arasındaki değerler kabul edilebilir bir model göstergesi olarak alınmaktadır. Bu durum gözlenen değişkenler arasında kovaryansın hesaplandığı anlamına gelmektedir (Bayram, 2013). RMSA Uyum İndeksi ana kütlede ortaya çıkabilecek beklenen her bir serbestlik derecesinin ortalama farklarını karşılaştıran kesin bir uygunluk ölçüsüdür. $\mathrm{Bu}$ indeksin örneklem büyüklüğ̈̈ tarafindan olumsuz etkilendiği düşünülür. RMSA Uyum İndeksinin 0,05 ve daha az değeri iyi uyumu (Bayram, 2013), 0,05 ile 0,08 arasındaki değerleri kabul edilebilir uyumu göstermektedir (Çemberci, 2012). 
Tablo 2. Model Uyum Değerleri

\begin{tabular}{|l|c|c|}
\hline Uyum Ölçekleri & İyi Uyum Değerleri & Model Uyum Değerleri \\
\hline CMIN/DF & $<3$ & 0,613 \\
\hline CFI & $0,9<\mathrm{CFI}<1$ & 1,000 \\
\hline AGFI & $0,9<\mathrm{AGFI}<1$ & 0,963 \\
\hline GFI & $0,9<\mathrm{GFI}<1$ & 0,993 \\
\hline RMSEA & $0<\mathrm{RMSEA}<0,05$ & 0,000 \\
\hline
\end{tabular}

Tablo 2' de görüldüğü gibi modelin uyum değerleri iyi uyumu göstermektedir. Ayrıca CMIN testi P değeri 0,690 olduğundan anlamlı olmayan değerdir. CMIN testinin anlamlı olmayan değeri ana kütle kovaryans matrisinin modelden üretilen kovaryans matrisine eşit olduğunu göstermektedir. Bu da modelin tutarlı olduğunu göstermektedir.

\section{Sonuç}

Hipotezleri test etmek için AMOS veri işleme programında yapısal eşitlik analizi yapılmıştır. Hipotezlere ait Standart $\beta$, C.R. ve P değerleri ile kabul ve ret sonuçları Tablo 3.'de gösterilmektedir.

Tablo 3. Yol Analizi Sonuçları

\begin{tabular}{|c|c|c|l|l|}
\hline Hipotezler & Standart $\boldsymbol{\beta}$ & C.R. & P & Kabul/Ret \\
\hline $\mathrm{H}_{1}$ & 0,550 & 2,293 & 0,022 & Kabul \\
\hline $\mathrm{H}_{2}$ & $-0,157$ & $-0,922$ & 0,357 & Ret \\
\hline $\mathrm{H}_{3}$ & 0,077 & 0,252 & 0,801 & Ret \\
\hline $\mathrm{H}_{4}$ & 0,273 & 1,185 & 0,236 & Ret \\
\hline $\mathrm{H}_{5}$ & $-0,206$ & $-1,099$ & 0,272 & Ret \\
\hline $\mathrm{H}_{6}$ & 0,913 & 3,193 & 0,001 & Kabul \\
\hline
\end{tabular}

$\mathrm{H}_{1}$ hipotezi ve $\mathrm{H}_{6}$ hipotezi 0,05 anlamlılık düzeyinde kabul edilmiş olup diğer hipotezler reddedilmiştir. $\mathrm{Bu}$ durumda Lojistik Performans Endeksinin boyutlarından Gümrüklerin ve Gümrükleme Süreçlerinin Verimliliği ile Ticaret ve Taşımacılıkla İlgilli Altyapı Kalitesi Gayrisafi Milli Hasıla üzerinde pozitif etkisi olduğu istatistiksel olarak anlamlı bulunmuştur. Gümrüklerin ve Gümrükleme Süreçlerinin iyileştirilmesi ve Ticaret ve Taşımacılıkla İlgili Altyapı Kalitesini yükseltecek yatırımlar yapılması ülkenin GSMH'sinde bir artışa sebep olacağı söylenebilir. 


\section{REFERENCES}

- Agility. (2014). Agility Emerging Markets Logistics Index 2014. Transport Intelligence.

- Arvis, J.-F., Saslavsky, D., Ojala, L., Shepherd, B., Busch, C., \& Raj, A. (2014). The Logistics Performance Index and Its Indicators. Washington: The Word Bank.

- Bayraktutan, P. D., Tüylüoğlu, D. D., \& Özbilgin, A. G. (2012). Lojistik Sektöründe Yoğunlaşma Analizi ve Lojistik Gelişmişlik Endeksi:Kocaeli örneği . Uluslararası Alanya İşletme Fakültesi Dergisi, 61-71.

- Bayram, N. (2013). Yapısal Eşitlik Modellemesine Giriş. BURSA: Ezgi Yayınevi.

- Burmaoğlu, S. (2012). Ulusal İnovasyon Göstergeleri ile Ulusal Lojistik Performans1 Arasında İlişki:AB Ülkeleri Üzerine Bir Araştırma . Ege Akademik Bakış, 193-208.

- Çemberci, M. (2012). Tedarik Zinciri Yönetimi Performansının Göstergeleri ve Firma Performansı Üzerine Etkileri: Kavramsal Model Önerisi. İSTANBUL: Akademi Titiz Yayınları.

- Deloitte. (2013). The Logistics Industry in Turkey. Deloitte.

- Dursun, Y., \& Kocagöz, E. (2010). Yapısal Eşitlik Modellemesi ve Regresyon: Karşılaştırmalı Bir Analiz. Erciyes Üniversitesi, İİBF Dergisi(35), 1-17.

- Loder. (2014, 3 21). 01 15, 2014 tarihinde Lojistik derneği Web Sitesi: www.loder.org.tr adresinden alınd 1

- Meydan, C. H., \& Şeşen, H. (2011). Yapısal Eşitlik Modellemesi AMOS Uygulamaları. ANKARA: Detay Yayıncilik.

- Müsiad. (2013). LOJISTIKK SEKTÖR RAPORU. İstanbul: Müsiad.

- RYKGM, E. A. (2014). CONNECTING TO COMPETE 2014 "The Logistics Performance Index and Its Indicators. Ankara: T.C. Gümrük Bakanlığı.

- Tanyas, P. D., \& Arıkan, F. (2013). BURSA İLİ LOJISTIIK MERKEZ ÖN FİZİBILİTE RAPORU. Bursa: T.C. Kalkınma Bakanlığı.

- UND. (2014, 07 04). 01 02, 2015 tarihinde Uluslararası Nakliyeciler Derneği Web sitesi: http://www.und.org.tr adresinden alınd1. 